\title{
Fourier Transform Microwave Spectroscopy of Criegee Intermediates: The Conformational Behaviour of Butyraldehyde Oxide
}

\author{
Carlos Cabezas, ${ }^{1, a)}$ Jean-Claude Guillemin, ${ }^{2}$ Yasuki Endo ${ }^{1, b)}$ \\ ${ }^{1}$ Department of Applied Chemistry, Science Building II, National Chiao Tung University, 1001 Ta-Hsueh \\ Rd., Hsinchu 30010, Taiwan \\ ${ }^{2}$ Univ Rennes, Ecole Nationale Supérieure de Chimie de Rennes, CNRS, ISCR - UMR6226, F-35000 \\ Rennes, France. \\ ${ }^{a)}$ Present address: Grupo de Astrofísica Molecular, Instituto de Física Fundamental (IFF), Consejo \\ Superior de Investigaciones Científicas, Calle Serrano 121, Madrid, Spain \\ b) Author to whom correspondence should be addressed. Electronic mail: endo@nctu.edu.tw
}

\begin{abstract}
Four conformers of the $n$-propyl-substituted Criegee intermediate, $\mathrm{CH}_{3} \mathrm{CH}_{2} \mathrm{CH}_{2} \mathrm{CHOO}$, named also $n$-butyraldehyde oxide have been observed by Fourier transform microwave spectroscopy. The transient species was produced using a pulsed electric discharge of a gas mixture of 1,1diiodobutane/ $\mathrm{O}_{2}$ diluted in $\mathrm{Ar}$ or Ne. The observation of only syn species is in contrast to the results of other previous studies of alkyl-substituted Criegee intermediates, in particular those for the structural isomers, isobutyraldehyde oxide $\left(\left(\mathrm{CH}_{3}\right)_{2} \mathrm{CHCHOO}\right)$ and methyl-ethyl-ketone oxide $\left(\mathrm{C}_{2} \mathrm{H}_{5} \mathrm{C}\left(\mathrm{CH}_{3}\right) \mathrm{OO}\right)$, for which syn and anti species have been observed coexisting in the gas phase.
\end{abstract}




\section{INTRODUCTION}

Carbonyl oxides are important intermediates in the ozonolysis reaction of alkenes under atmospheric conditions. ${ }^{1}$ Their formation is attributed to ring-opening of primary ozonides (POZ) formed directly by the 1,3-cycloaddition reaction of ozone across the olefinic bond. Aldehydes and ketones are formed as co-products in these reactions. The simplest carbonyl oxide named formaldehyde oxide, $\mathrm{CH}_{2} \mathrm{OO}$, is also known as the Criegee intermediate (CI), after Rudolf Criegee who first proposed pathways for carbonyl oxide formation in alkene ozonolysis. ${ }^{2}$ Although the formation mechanism of carbonyl oxides was known since 1949, CIs and their reactivity could not be studied experimentally because of their short lifespan and lack of direct precursors. As a result, experimental data for CIs such as their rate coefficients were often determined indirectly with several assumptions and high uncertainties. However, Taatjes et al. ${ }^{3}$ in 2008 generated the simplest $\mathrm{CI}, \mathrm{CH}_{2} \mathrm{OO}$, using photolysis of $\mathrm{CH}_{2} \mathrm{I}_{2}$ in $\mathrm{O}_{2}$. This method has been demonstrated as an efficient route to the formation of the simplest CI with yields high enough to perform direct kinetic or spectroscopic measurements. ${ }^{4}$ Making use of this method to generate $\mathrm{CH}_{2} \mathrm{OO}$, several spectroscopic studies, including ultraviolet experiments, ${ }^{5-8}$ infrared absorption spectroscopy, ${ }^{9}$ Fourier transform microwave experiments ${ }^{10-12}$ and millimeter wave measurements, ${ }^{13}$ have been devoted to characterize the structure and reactivity of this species in the gas phase. Analogous routes have been used to synthesize larger CIs, such as alkylderivatives. ${ }^{14-15}$ Consequently it has stimulated active research on these important species making it an exciting field of research with many scientific publications every year.

The atmospheric significance of CIs has been discussed for decades, and such compounds are thought to play important roles in atmospheric chemistry due to their high reactivity. Significant amounts of CIs are consumed in the atmosphere by reactions with scavengers, such as organic acids, aldehydes, $\mathrm{SO}_{2}, \mathrm{HO}_{\mathrm{x}}, \mathrm{H}_{2} \mathrm{O}, \mathrm{O}_{3}$, and $\mathrm{NO}_{\mathrm{x}}$, and with themselves, ${ }^{16-18}$ leading to the formation of secondary organic aerosols. ${ }^{16}$ The kinetics of these reactions have been deeply investigated and a strong structure dependence has been revealed. ${ }^{19}$ Alkyl-substituted CIs, formed in the ozonolysis of large alkenes, display conformational isomerism due to the presence of distinct substituent groups in their structure. In the simplest cases, such as acetaldehyde oxide, $\mathrm{CH}_{3} \mathrm{CHOO}$, two different configurations are possible, syn and anti, which show very different reactivities. For instance, the rate coefficients of the unimolecular decomposition of syn- $\mathrm{CH}_{3} \mathrm{CHOO}$ is on the order of $10^{2} \mathrm{~s}^{-1}$ at $298 \mathrm{~K}^{20}$ while for the anti- $\mathrm{CH}_{3} \mathrm{CHOO}$ the measured values indicate that the self-reaction is much slower. ${ }^{21,22}$ In contrast, anti- $\mathrm{CH}_{3} \mathrm{CHOO}$ is substantially more reactive toward water than syn- $\mathrm{CH}_{3} \mathrm{CHOO}^{23,24}$ In the cases of larger CIs the number of possible conformers increases. This is the case of $\mathrm{C}_{2} \mathrm{H}_{5} \mathrm{CHOO}$ where the ethyl part confers flexibility to the molecular system and extra conformations can be adopted. In fact, the 
observation of four different species of $\mathrm{C}_{2} \mathrm{H}_{5} \mathrm{CHOO}$ has been reported recently. ${ }^{25,26}$ Understanding of the reactivity of CIs requests the knowledge of their structural features. Thus, investigations of the intrinsic conformational preferences of these important atmospheric species constitute the first scenario.

In the present work we report the conformational investigation of the $n$-butyraldehyde oxide $\left(\mathrm{C}_{3} \mathrm{H}_{7} \mathrm{CHOO}\right.$, denoted in this work as NPCI) using Fourier-transform microwave (FTMW) spectroscopy. NPCI has two other structural isomers; isobutyraldehyde oxide $\left(\left(\mathrm{CH}_{3}\right)_{2} \mathrm{CHCHOO}\right)$ and methyl-ethyl-ketone oxide $\left(\mathrm{C}_{2} \mathrm{H}_{5} \mathrm{C}\left(\mathrm{CH}_{3}\right) \mathrm{OO}\right)$, which have been investigated in our laboratory in an attempt to carry out a systematic conformational study. ${ }^{26-28}$ For isobutyraldehyde oxide and methyl-ethyl-ketone oxide three and four different conformers, respectively, were observed in the gas phase including syn- and anti-isomers. The present study will reveal the effect of a larger alkyl-chain for the conformational preferences in $n$ butyraldehyde oxide, compared to other substituents with the same number of carbons but small chain-length.

\section{MOLECULAR ORBITAL CALCULATIONS}

Initial searches for minimum energy structures for the NPCI were conducted using the B3LYP/cc-pVTZ level of theory. The different conformations found were then optimized at the CCSD/cc-pVTZ level of theory (geometries are shown in Table SI of Supplementary Material) to ascertain their relative stabilities as well as the rotational parameters necessary to predict rotational transition frequencies before the spectral survey. Vibrational frequency calculations at the CCSD/cc-pVTZ level of theory were carried out to provide the Gibbs free energies for the conformers that were confirmed to be local minima in the potential energy surface by checking that their Hessian matrix did not have any imaginary eigenvalues. All the calculations were carried out using the Molpro 2012.1 ab initio program package. ${ }^{29}$ A total of nine conformers (see Figure 1), four syn and five anti, were found in an energy window of $1400 \mathrm{~cm}^{-1}$. The relative energies of the conformers are listed in Table 1 , and molecular properties relevant for our rotational studies, namely rotational constants and dipole moment components, are shown in Table 2 and Table SII of the Supplementary Material for the syn and the anti conformers, respectively.

\section{EXPERIMENTAL}

The experimental measurements were conducted using a Balle-Flygare narrow-band type Fourier-transform microwave (FTMW) spectrometer operating in the frequency region of 4-40 GHz. ${ }^{30}$ The short-lived species, was produced in a supersonic expansion by a pulsed electric 
discharge of a gas mixture of 1,1-diiodobutane, which was synthesized using the method outlined below, and oxygen heavily diluted in argon or neon gas. 1,1-diiodobutane ${ }^{31}$ was prepared on a $0.1 \mathrm{~mol}$ scale using the synthesis of Friedrich et al. ${ }^{32}$ for 1,1-diiodoethane but starting from butyraldehyde. The product was purified by distillation in vacuo $\left(\mathrm{bp}_{0.1}: 47^{\circ} \mathrm{C}\right)$ and obtained in a $46 \%$ yield.

The mixture of gases, $2 \% \mathrm{O}_{2}$ and $98 \%$ Ar or Ne, with the total pressure of $1.5 \mathrm{~atm}$ was passed through a container filled with liquid 1,1-diiodobutane in order to introduce the precursor molecules with a sufficient partial pressure. The gas mixture (1,1-diiodobutane, $\mathrm{O}_{2}$ and $\mathrm{Ar}$ or $\mathrm{Ne}$ ) was flowed through a pulsed-solenoid valve that is accommodated in the backside of one of the cavity mirrors and aligned parallel to the optical axis of the resonator. A pulsed voltage of $800 \mathrm{~V}$ with a duration of $450 \mu$ s was applied between two stainless steel electrodes attached at the exit of the nozzle of the pulsed valve, ${ }^{33}$ resulting in an electric discharge synchronized with the gas expansion. During the experiment, the pressure inside the vacuum chamber equipped with the cavity was kept at $6.0 \times 10^{-5}$ Torr with a pulsed valve operated at a repetition rate of 10 Hz. The resulting products generated in the discharge were supersonically expanded, rapidly cooled to a rotational temperature of $\sim 2.5 \mathrm{~K}$ between the two mirrors of the Fabry-Pérot resonator, and then probed by Fourier-transform microwave spectroscopy. MW-MW doubleresonance techniques ${ }^{34}$ were also used for observing pure rotational transitions and confirming the assignments of those observed by FTMW spectroscopy.

\section{RESULTS}

Due to the large number of plausible populated conformers of NPCI a wide frequency region was scanned, the chosen region was from 10 to $16 \mathrm{GHz}$ due to the better performance of the spectrometer, to have an overall view of the NPCI rotational spectrum. A great number of rotational transitions were observed and most of them were confirmed as discharge products by repeating the scans in absence of electric discharge. The frequencies of the most intense lines were analyzed in the first attempt, trying to assign any of the syn species, predicted more stable than the anti ones. We assigned four different species using these intense lines, but the sets of the rotational constants were completely different from those predicted for the syn or anti conformers of NPCI. Finally they were assigned as the four conformers of $n$-butanal, which has been previously identified in the gas phase by Hotopp et al. ${ }^{35}$

After removing all the lines of the four conformers of $n$-butanal, several weaker lines still remain unassigned. All these lines appear as single lines without any fine or hyperfine structure associated. The analysis of these lines provided the assignment of other four different species. For all the detected conformers $a$ - and $b$-type rotational transitions were observed, and in 
addition $c$-type transitions were measured for one of them, which finally was identified as the conformer syn3. The other three observed species were syn1, syn2 and syn4. The experimental rotational constants for these four conformers were determined by least-squares fits of the transition frequencies (Tables SIII-SVI of Supplementary Material) using Watson's A-reduced ${ }^{1} \Sigma$ Hamiltonian, ${ }^{36}$ and the results are summarized in Table 3 . The identification could be easily achieved by comparing the experimentally determined spectroscopic constants with those predicted $a b$ initio. The calculated constants in Table 2 show maximum deviations from experimental values of $1.4 \%$, indicating that the calculated $a b$ initio geometries are fairly accurate.

After surveying the rotational transitions of the syn conformers much weaker rotational transitions prevail unassigned. They may belong to the anti conformers which are predicted to be about $1000-1300 \mathrm{~cm}^{-1}$ less stable than the syn-species. Several attempts to fit these remaining lines to any of the anti conformers were carried out, but they prevail unassigned. Furthermore, exhaustive additional searches were done to look for spectral signatures of anti conformers but no lines belonging to any other conformer were observed in the spectrum.

All these mentioned experiments were done using the gas mixture of $2 \% \mathrm{O}_{2}$ diluted in Ar. In the second part of the experiments we changed $\mathrm{Ar}$ with $\mathrm{Ne}$ as the carrier gas, repeating all the frequency scans. In a previous study ${ }^{26}$ we found significant differences when Ar or Ne was chosen as the carrier gas due to their different cooling efficiency in supersonic expansions. ${ }^{37,38}$ In fact, an Ar-seeded expansion is expected to favor conversion of higher energy conformers to lower ones, while higher energy species will survive in a Ne-seeded expansion. Although synand anti-species cannot interconvert with each other, the presence of Ar or Ne could affect to the formation processes of both species. Unfortunately, the new scans did not show any differences with those performed with Ar as the seeding gas including the relative intensities between the $n$-butanal and NPCI, and those among the four conformers of NPCI.

\section{DISCUSSION}

As shown in previous studies of alkyl-substituted Criegee intermediates, such as $\mathrm{CH}_{3} \mathrm{CHOO},{ }^{14,39}$ $\mathrm{C}_{2} \mathrm{H}_{5} \mathrm{CHOO}^{25}$ and $\left(\mathrm{CH}_{3}\right)_{2} \mathrm{CHCHOO}^{26}$ the syn conformers are predicted to be the preferred configurations. This major stability can be ascribed to the attractive interaction between the terminal oxygen atom and the protons of the closer carbon atom of the alkyl moiety. The terminal oxygen has three lone-pairs in a zwitterionic canonical structure, $\mathrm{C}_{n} \mathrm{H}_{\mathrm{m}} \mathrm{CH}=\mathrm{O}^{\oplus}-\mathrm{O} \ominus$, which is considered to contribute significantly to the ground state electronic structure at least in $\mathrm{CH}_{2} \mathrm{OO} .{ }^{10}$ Two of the three lone-pairs, occupying the valence $s p^{3}$ orbital, seem to be interacting with the protons of the $-\mathrm{CH}_{2}-$ protons in the case of syn conformers. This stabilizing interaction 
cannot occur in any of the anti conformers of NPCI, hence their lower stability compared to the syn conformers. The non observation of anti conformers for NPCI is in contrast with the results of all the previous studies of alkyl-substituted CIs, ${ }^{14,25-27,39}$ in which both syn and anti conformations were detected coexisting in the gas phase, even when the energetic difference between them was similar to that for NPCI (around $1000 \mathrm{~cm}^{-1}$ ). The concentration syn/anti ratios were found to be around 5 for these alkyl-substituted CIs, such as $\mathrm{CH}_{3} \mathrm{CHOO}^{14,39}$ and $\mathrm{C}_{2} \mathrm{H}_{5} \mathrm{CHOO},{ }^{25}$ in accordance with the relative energy predictions assuming the temperature of $1100 \mathrm{~K}$. Attending to our calculations anti species of NPCI should be present in our supersonic expansion in detectable amounts but no traces of these conformers were found. As shown before, the four conformers of $n$-butanal ${ }^{35}$ were also produced in our experiment in a significant amount. In the above mentioned studies of alkyl-substituted CIs, where similar precursors were used, we observed their corresponding aldehydes formed as secondary products in the electric discharge in addition to the CIs. For example, in the case of $\mathrm{C}_{2} \mathrm{H}_{5} \mathrm{CHOO}^{25}$ and $\left(\mathrm{CH}_{3}\right)_{2} \mathrm{CHCHOO}^{26}$ studies, we observed the rotational spectra of propionaldehyde and isobutyraldehyde, respectively. The main difference with the present case is the abundances of these aldehydes. While for $\mathrm{C}_{2} \mathrm{H}_{5} \mathrm{CHOO}$ and $\left(\mathrm{CH}_{3}\right)_{2} \mathrm{CHCHOO}$ the abundances of the aldehydes were $\sim 20 \%$ lower than those for the CIs, in the NPCI experiment the most intense lines correspond to $n$-butanal, for which concentration has been estimated to be 4-5 times larger than that for NPCI conformers. The formation of these aldehydes, including $n$-butanal, from the corresponding CIs only requires the release of the terminal oxygen. Thus, the high concentration of $n$-butanal in our experiment can be associated with a faster decomposition of NPCI, compared to other CIs. Probably, the reaction to produce $n$-butanal from NPCI is more rapid for the anti conformers, which decreases its concentration in the gas phase and consequently inhibit its observation.

As mentioned in the introduction NPCI is a $\mathrm{C}_{4}$ family CI with two other structural isomers; $\left(\mathrm{CH}_{3}\right)_{2} \mathrm{CHCHOO}^{26}$ and $\mathrm{C}_{2} \mathrm{H}_{5} \mathrm{C}\left(\mathrm{CH}_{3}\right) \mathrm{OO}^{27}$ which have been recently investigated in our lab as well. Three conformers were observed in the case of $\left(\mathrm{CH}_{3}\right)_{2} \mathrm{CHCHOO}$ among the four conformers predicted in an energy window of $\sim 1300 \mathrm{~cm}^{-1}$, being the two syn species the most stable ones. The non-observation of one anti conformer was ascribed to an interconversion process to the other anti conformer taking place during the supersonic expansion. The $\mathrm{C}_{2} \mathrm{H}_{5} \mathrm{C}\left(\mathrm{CH}_{3}\right) \mathrm{OO}$ case is slightly different from NPCI and $\left(\mathrm{CH}_{3}\right)_{2} \mathrm{CHCHOO}$ because $\mathrm{C}_{2} \mathrm{H}_{5} \mathrm{C}\left(\mathrm{CH}_{3}\right) \mathrm{OO}$ is a doubly-substituted $\mathrm{CI}$ and the energy differences between the plausible conformers are much smaller. Two syn and two anti species were predicted with energy difference within $200 \mathrm{~cm}^{-1}$, and all of them were detected coexisting in the gas phase. In contrast, the length of the alkyl chain makes NPCI to have a larger number of energetically 
accessible conformers, up to nine with energies below $1400 \mathrm{~cm}^{-1}$, and unlike the cases for $\left(\mathrm{CH}_{3}\right)_{2} \mathrm{CHCHOO}$ and $\mathrm{C}_{2} \mathrm{H}_{5} \mathrm{C}\left(\mathrm{CH}_{3}\right) \mathrm{OO}$ only the syn species, predicted as most stable ones, have been detected. Therefore, the conformational richness of NPCI can be another fact that restricted our observations only to the syn species, since the number of possible states is larger, compared to other studied systems, making the intensity of the spectral transitions become smaller.

The alkyl-substituent of the NPCI system has a longer chain, compared to those of other CIs studied so far, and this chain can provide larger cross sections in collisional environment at the first stages of the supersonic expansion. That means that the effective temperature of the system will be lower than that for other CIs with smaller alkyl-substituents. For related systems such as $\mathrm{CH}_{3} \mathrm{CHOO},{ }^{14,39} \mathrm{C}_{2} \mathrm{H}_{5} \mathrm{CHOO}^{25}$ and $\mathrm{C}_{2} \mathrm{H}_{5} \mathrm{C}\left(\mathrm{CH}_{3}\right) \mathrm{OO}^{27}$ the temperature at which the reaction to form the CIs occurs was estimated to be around $1100 \mathrm{~K}$. This value explains approximately the relative abundances of the syn and anti species in such cases. In contrast, for NPCI the effective temperature seems to be much lower due to effect of the alkyl chain. In Table 4, the relative populations for all the conformers at $300 \mathrm{~K}$ and $1100 \mathrm{~K}$ calculated using the Gibbs free energies from Table 1, are shown. As can be seen, at $1100 \mathrm{~K}$ the estimated population of the anti conformers is high enough to be observed in our experiment, in fact, for some conformers the predicted abundances are comparable to that for syn 4 species. At lower temperatures, the population of the higher energy conformers, the anti ones, is almost negligible as shown in Table 4, where the populations were calculated at $300 \mathrm{~K}$.

In order to check the relative concentration of the syn conformers, the experimental relative populations of the observed conformers in the supersonic expansion were estimated by relative intensity measurements of the same rotational transitions. It is assumed that the supersonic expansion brings all conformers to their lowest vibrational state and that the intensity of the rotational transition is proportional to the number density of each conformer and the value of the corresponding component of the dipole moment, $N_{\mathrm{i}} \cdot \mu_{\mathrm{i}} \cdot N_{\mathrm{i}}$ corresponds to the molecules populating all the vibrational states of a given conformer at the first stages of the expansion, and $\mu_{\mathrm{i}}$ is the corresponding electric dipole moment component. From these measurements we found an approximate population ratio depicted in Table 4, with syn3 conformer being the most abundant species. These results agree better with the calculations at $300 \mathrm{~K}$ but conformers syn2 and syn3 show higher populations than expected. It should be noted that conformers syn1, syn3 and syn 4 have their equivalent (isoenergetic) counterparts differing in the sign of the $\angle$ CCCC dihedral angle. However, this is not the case for syn2 because of the planarity of its backbone. The ratios between the pairs of conformers syn1/syn 4 and syn2/syn3 are almost the same for the experimental and theoretical cases. This fact can be related to the structural arrangement of the 
alkyl-substituent. The relative disposition adopted by the $\angle$ OCCC dihedral angle for syn2 and syn3 conformers is a trans while that for syn 1 and syn 4 is gauche, as can be seen in the Figure 1. This arrangement can affect their different unimolecular decay to form $\mathrm{OH}$ radicals. For the ethyl-substituted $\mathrm{CI}, \mathrm{C}_{2} \mathrm{H}_{5} \mathrm{CHOO},{ }^{20}$ it has shown that conformer syn2, with a gauche arrangement for $\angle$ OCCC, shows a faster unimolecular decay rate (around $30 \%$ faster) in the decomposition process to $\mathrm{OH}$ products than conformer syn1, whose arrangement for $\angle \mathrm{OCCC}$ is trans. Assuming a similar behavior for the NPCI, where the syn1/syn4 conformers decompose to $\mathrm{OH}$ products faster than the syn2/syn3 conformers do, their relative conformational abundances will be changed with a smaller amount of syn1/syn4 species, justifying the discrepancies between the theoretical and the experimental values.

As can be seen in Figure 2, none of rotational transitions for the four observed conformers of NPCI shows any splittings, such as $A / E$ splittings due to the internal rotation, despite the presence of a methyl group in the molecule. In contrast, $A / E$ splittings produced by the internal rotation motion of either $\mathrm{CH}_{3}$ - or $\mathrm{C}_{2} \mathrm{H}_{5}$ - tops were observed for most of the conformers for related alkyl-substituted Criegee intermediates such as $\mathrm{CH}_{3} \mathrm{CHOO},{ }^{14,39}\left(\mathrm{CH}_{3}\right)_{2} \mathrm{COO},{ }^{40}$ $\mathrm{C}_{2} \mathrm{H}_{5} \mathrm{CHOO}^{25}$ and $\mathrm{C}_{2} \mathrm{H}_{5} \mathrm{C}\left(\mathrm{CH}_{3}\right) \mathrm{OO}{ }^{27,28}$ The experimentally observed values of the $V_{3}$ barrier heights for the hindered internal rotation were found to be from $399 \mathrm{~cm}^{-1}$, the smaller value for anti- $\mathrm{CH}_{3} \mathrm{CHOO}$, up to $953 \mathrm{~cm}^{-1}$, the larger value in the case of $\mathrm{C}_{2} \mathrm{H}_{5} \mathrm{C}\left(\mathrm{CH}_{3}\right) \mathrm{OO}$, being the differences associated to steric hindrances. In this study, we estimated the $V_{3}$ methyl internal rotation barrier heights at the CCSD/cc-pVTZ level of theory for all the observed conformers of NPCI and we found them to be between $1140-1220 \mathrm{~cm}^{-1}$. These values are too high to observe any $A / E$ splittings in our spectra despite the subdoppler resolution associated to our spectrometer.

\section{CONCLUSION}

The conformational behavior of the $n$-propyl-substituted Criegee intermediate $\left(\mathrm{C}_{3} \mathrm{H}_{7} \mathrm{CHOO}\right)$ has been investigated through FTMW spectroscopy. The $\mathrm{C}_{3} \mathrm{H}_{7}$ - alkyl chain confers high flexibility to the molecular system and the number of energetically accessible conformers increases compared to those for related systems such as the structural isomers isobutyraldehyde oxide $\left(\left(\mathrm{CH}_{3}\right)_{2} \mathrm{CHCHOO}\right)$ and methyl-ethyl-ketone oxide $\left(\mathrm{C}_{2} \mathrm{H}_{5} \mathrm{C}\left(\mathrm{CH}_{3}\right) \mathrm{OO}\right)$. A total of four synconformers were observed in the rotational spectrum but no spectral signatures for any of the anti-conformers were found in the spectrum. This result is quite different from our previous studies for related alkyl-substituted Criegee intermediates. Three possible reasons may be contributing to the non-observation of the anti species; (i) that the NCPI decomposes very fast to $n$-butanal, especially the anti-conformers; (ii) the large number of plausible conformers 
suggests that the population is distributed in many states and the individual contribution of each conformer will be lower than in other CIs with less accessible conformers and (iii) the $n$-propyl chain contributes to a lower effective temperature prior to the supersonic expansion and thus giving a lower concentration of higher energy conformers.

\section{SUPPLEMENTARY MATERIAL}

See Supplementary Material for the optimized geometries and measured transition frequencies for NPCI conformers.

\section{ACKNOWLEDGMENTS}

This research was supported by the Ministry of Science and Technology of Taiwan under Grant Nos MOST 104-2113-M-009-020 (Y.E.) and MOST 105-2811-M-009-026 and MOST 1052811-M-009-026 (C.C.). J.-C.G. thanks the Centre National d'Etudes Spatiales (CNES) and the Program PCMI (INSU-CNRS) for financial support.

\section{REFERENCES}

1. L. Vereecken and J. S. Francisco, Chem. Soc. Rev., 41, 6259 (2012).

2. R. Criegee and G. Wenner, Justus Liebigs Ann. Chem., 564, 9 (1949).

3. C. A. Taatjes, G. Meloni, T. M. Selby, A. J. Trevitt, D. L. Osborn, C. J. Percival, and D. E. Shallcross, J. Am. Chem. Soc. 130, 11883 (2008).

4. O. Welz, J. D. Savee, D. L. Osborn, S. S. Vasu, C. J. Percival, D. E. Shallcross and C. A. Taatjes, Science, 335, 204 (2012).

5. J. M. Beames, F. Liu, L. Lu, and M. I. Lester, J. Am. Chem. Soc. 134, 20045 (2012).

6. L. Sheps, J. Phys. Chem. Lett. 4, 4201(2013).

7. W.-L. Ting, Y.-H. Chen, W. Chao, M.C. Smith, and J. J.-M. Lin, Phys. Chem. Chem. Phys. 16, 10438 (2014).

8. R. Dawes, B. Jiang, and H. Guo, J. Am. Chem. Soc., 137, 50 (2015).

9. Y.-T. Su, Y.-H. Huang, H. A. Witek, and Y.-P. Lee, Science 340, 174 (2013).

10. M. Nakajima and Y. Endo, J. Chem. Phys. 139, 101103 (2013).

11. M. C. McCarthy, L. Cheng, K. N. Crabtree, O. Martinez, T. L. Nguyen, C. C. Womack, and J.F. Stanton, J. Phys. Chem. Lett. 4, 4133 (2013). 
12. C. C. Womack, M.-A. Martin-Drumel, G. G. Brown, R. W. Field, and M. C. McCarthy, Sci. Adv. 1, e1400105 (2015).

13. A. M. Daly, B. J. Drouin, and S. Yu, J. Mol. Spectrosc. 297, 16 (2014).

14. M. Nakajima and Y. Endo, J. Chem. Phys. 140, 011101 (2014).

15. F. Liu, J. M. Beames, A. M. Green, and M. I. Lester, J. Phys. Chem. A 118, 298 (2014).

16. D. Johnson, G. Marston, Chem. Soc. Rev. 37, 699 (2008).

17. D. L. Osborn and C. A. Taatjes, Int. Rev. Phys. Chem., 34, 309, (2015).

18. T. B. Nguyen, G. S. Tyndall, J. D. Crounse, A. P. Teng, K. H. Bates, R. H. Schwantes, M. M. Coggon, L. Zhang, P. Feiner, D. O. Milller, K. M. Skog, J. C. Rivera-Rios, M. Dorris, K. F. Olson, A. Koss, R. J. Wild, S. S. Brown, A. H. Goldstein, J. A. de Gouw, W. H. Brune, F. N. Keutsch, J. H. Seinfeld and P. O. Wennberg, Phys. Chem. Chem. Phys., 18, 10241 (2016).

19. R. Atkinson, J. Phys. Chem. Ref. Data 26, 215 (1997).

20. Y. Fang, F. Liu, V. P. Barber, S. J. Klippenstein, A. B. McCoy and M. I. Lester, J. Chem. Phys. 145, 234308. (2016)

21. L. Vereecken, D. R. Glowacki and M. J. Pilling, Chem. Rev. 115, 4063 (2015).

22. T. Berndt, R. Kaethner, J. Voigtländer, F. Stratmann, M. Pfeifle, P. Reichle, M. Sipilä, M. Kulmala and M. Olzmann, Phys. Chem. Chem. Phys. 17, 19862 (2015).

23. C. A. Taatjes, O. Welz, A. J. Eskola, J. D. Savee, A. M. Scheer, D. E. Shallcross, B. Rotavera, E. P. F. Lee, J. M. Dyke, D. K. W. Mok, D. L. Osborn, and C. J. Percival, Science 340, 177 (2013).

24. L. Sheps, A. M. Scully and K. Au, Phys. Chem. Chem. Phys. 16, 26701 (2014).

25. C. Cabezas, J.-C. Guillemin, and Y. Endo, J. Chem. Phys., 145, 224314 (2016).

26. C. Cabezas, J.-C. Guillemin, and Y. Endo, J. Chem. Phys., 149, 084309 (2018).

27. C. Cabezas, J.-C. Guillemin, and Y. Endo, J. Chem. Phys., 146, 174304 (2017).

28. C. Cabezas, I. Kleiner, M. Carvajal, and Y. Endo, J. Mol. Spectrosc., 353, 23 (2018). 
29. H.-J. Werner, P. J. Knowles, G. Knizia, F. R. Manby, M. Schütz et al., MOLPRO, version 2012.1, a package of $a b$ initio programs, 2012, see http://www.molpro.net.

30. C. Cabezas, J.-C. Guillemin, and Y. Endo, J. Chem. Phys., 145, 184304 (2016).

31. A. García Martínez, R. Martínez Álvarez, S. Martínez González, L. R. Subramanian, and M. Conrad, Tetrahedron Lett. 33(15), 2043 (1992).

32. E. C. Friedrich, S. N. Falling, and D. E. Lyons, Synth. Commun. 5, 33 (1975).

33. Y. Endo, H. Kohguchi, and Y. Ohshima, Faraday Discuss. 97, 341 (1994).

34. Y. Sumiyoshi, H. Katsunuma, K. Suma, and Y. Endo, J. Chem. Phys. 123, 054324 (2005).

35. K. M. Hotopp, V. V. Vara, and B. C. Dian, J. Mol. Spectrosc., 280, 104 (2012).

36. J. K. G. Watson, J. Chem. Phys. 46, 1935 (1967).

37. R. S. Ruoff, T. D. Klots, T. Emilsson, and H. S. Gutowsky, J. Chem. Phys. 93, 3142 (1990).

38. U. Erlekam, M. Frankowski, G. von Helden and G. Meijer, Phys. Chem. Chem. Phys. 9, 3786 (2007).

39. M. Nakajima, Q. Yue, and Y. Endo, J. Mol. Spectrosc. 310, 109 (2015).

40. M. Nakajima and Y. Endo, J. Chem. Phys. 145, 244307 (2016). 
Table 1. Calculated relative energies and Gibbs free energies at CCSD/cc-pVTZ level for NPCI conformers. Each of the syn and anti conformers is labeled with a number taking into account its relative stability.

\begin{tabular}{crrr}
\hline \hline & $\Delta E^{\mathrm{a}} / \mathrm{cm}^{-1}$ & $\Delta G(300 \mathrm{~K}) \mathrm{b}^{\mathrm{b}} / \mathrm{cm}^{-1}$ & $\Delta G(1100 \mathrm{~K}) \mathrm{b} / \mathrm{cm}^{-1}$ \\
\hline syn1 & 0 & 202 & 495 \\
syn2 & 19 & 0 & 0 \\
syn3 & 106 & 143 & 287 \\
syn4 & 161 & 351 & 634 \\
anti1 & 1095 & 1045 & 898 \\
anti2 & 1109 & 1034 & 748 \\
anti3 & 1133 & 1043 & 715 \\
anti4 & 1199 & 1231 & 1265 \\
anti5 & 1346 & 1263 & 910 \\
\hline
\end{tabular}

${ }^{a}$ Relative energy to that of syn1.

${ }^{\mathrm{b}}$ Relative energy to that of syn2.

Table 2. Theoretical spectroscopic constants for the syn conformers of NPCI calculated at CCSD/cc-pVTZ level.

\begin{tabular}{crrrr}
\hline \hline & syn1 & syn2 & syn3 & syn4 \\
\hline$A / \mathrm{MHz}$ & 7466 & 10953 & 9710 & 6607 \\
$B / \mathrm{MHz}$ & 2033 & 1566 & 1698 & 2170 \\
$\mathrm{C} / \mathrm{MHz}$ & 1761 & 1405 & 1603 & 2060 \\
$\mid \mu_{a} / \mathrm{D}$ & 2.8 & 5.1 & 5.8 & 4.1 \\
$\mid \mu_{b} / / \mathrm{D}$ & 4.8 & 3.4 & 1.4 & 3.8 \\
$\mid \mu_{c} / \mathrm{D}$ & 0.2 & 0.0 & 1.7 & 1.0 \\
\hline \hline
\end{tabular}


Table 3. Rotational constants for the four observed conformers of NPCI.

\begin{tabular}{ccccc}
\hline \hline & syn1 & syn2 & syn3 & syn4 \\
\hline$A / \mathrm{MHz}$ & $7544.8040(24)^{\mathrm{a}}$ & $10932.8951(18)$ & $9704.5022(14)$ & $6576.2082(56)$ \\
$B / \mathrm{MHz}$ & $2003.7535(20)$ & $1564.56066(54)$ & $1692.52342(50)$ & $2164.77142(63)$ \\
$C / \mathrm{MHz}$ & $1741.8070(20)$ & $1404.50934(49)$ & $1599.67713(50)$ & $2058.97922(60)$ \\
$\Delta_{J} / \mathrm{kHz}$ & $1.1182(15)$ & $0.179(33)$ & $0.486(13)$ & $2.5171(43)$ \\
$\Delta_{J K} / \mathrm{kHz}$ & $-6.720(90)$ & $-1.926(32)$ & $-5.114(71)$ & $-17.694(59)$ \\
$\Delta_{K} / \mathrm{kHz}$ & $31.50(52)$ & - & - & $53.9(11)$ \\
$\delta_{J} / \mathrm{kHz}$ & $0.02630(75)$ & $0.0290(42)$ & - & $0.0934(51)$ \\
$\delta_{K} / \mathrm{kHz}$ & $3.14(93)$ & - & $11.2(25)$ & - \\
$N^{\mathrm{b}}$ & 16 & 19 & 16 & 18 \\
$\sigma / \mathrm{kHz}$ & 2.1 & 2.1 & 2.7 & 2.6 \\
\hline \hline
\end{tabular}

${ }^{\mathrm{a}}$ Values in parentheses denote $1 \sigma$ errors, applied to the last digit.

${ }^{\mathrm{b}}$ Number of rotational transitions included in the fit.

Table 4. Theoretical relative abundances for NPCI conformers calculated using the Gibbs free energies from Table 1. The experimental relative abundances found for syn species are also shown.

\begin{tabular}{cccc}
\hline \hline & Rel. pop. $(300 \mathrm{~K})^{\text {a }}$ & Rel. pop. $(1100 \mathrm{~K})^{\mathrm{b}}$ & Rel. pop. Exp. \\
\hline syn1 & 2.1 & 1.2 & 2.5 \\
syn2 & 2.8 & 1.6 & 5.2 \\
syn3 & 2.9 & 1.2 & 5.7 \\
syn4 & 1.0 & 1.0 & 1.0 \\
anti1 & $5.6 \times 10^{-3}$ & 0.3 & - \\
anti2 & $4.4 \times 10^{-3}$ & 0.7 & - \\
anti3 & $1.1 \times 10^{-2}$ & 0.8 & - \\
anti4 & $3.8 \times 10^{-3}$ & 0.4 & - \\
anti5 & $1.2 \times 10^{-2}$ & 0.6 & - \\
\hline \hline & ${ }^{\mathrm{a}}$ Relative populations considering $\Delta G$ energies at $300 \mathrm{~K}$. & \\
${ }^{\mathrm{b}}$ Relative populations considering $\Delta G$ energies at $1100 \mathrm{~K}$.
\end{tabular}


Figure 1. Plausible conformers of NPCI obtained from $a b$ initio calculations at the CCSD/ccpVTZ level.

$\operatorname{syn} 1$

$\operatorname{syn} 2$

$\operatorname{syn} 3$

$\operatorname{syn} 4$
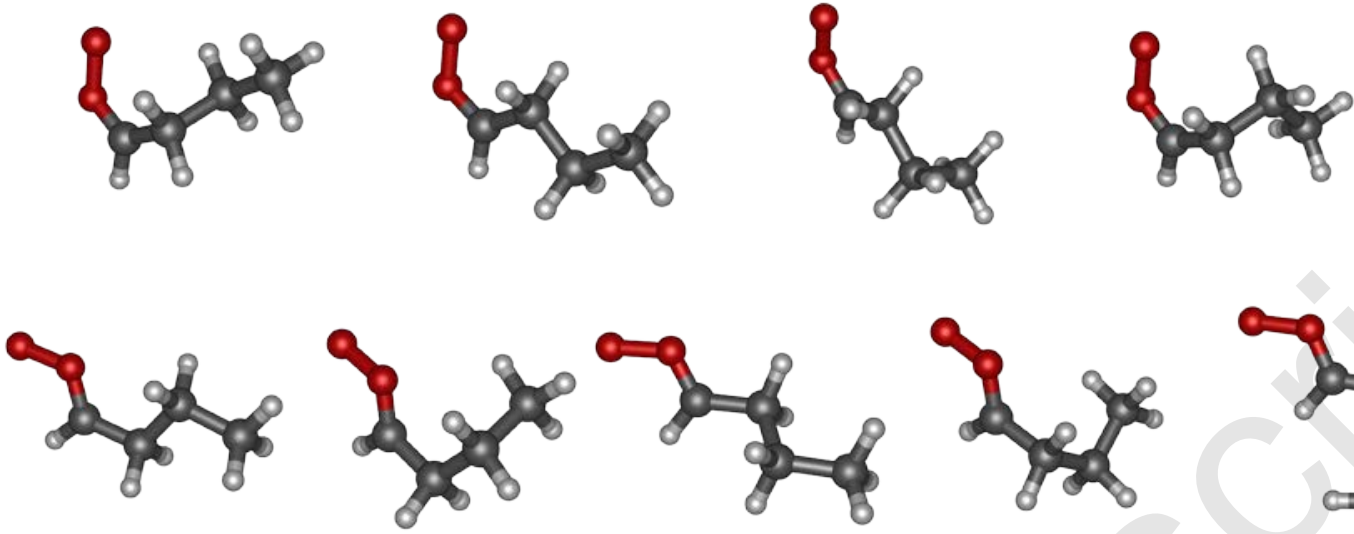

anti 1

anti 2

anti3

anti4

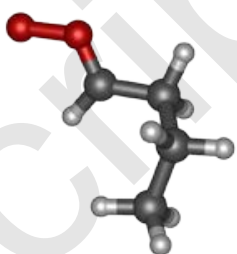

anti5 
Figure 2. A section of the FTMW spectrum of NPCI. The transitions marked with a circle correspond to NPCI, those signalized with an asterisk belong to $n$-butanal and those denoted with a triangle arise from non-discharge products. The rest of transitions without any marked are unidentified rotational transitions. The inset "a" corresponds to the $1_{10}-1_{01}$ rotational transition of the cis/trans conformer of $n$-butanal, while the "b", "c" and "d" insets are the $4_{14^{-}}$ $3_{13}, 2_{12}-1_{01}$ and $3_{12}-2_{11}$ rotational transitions of syn3, syn 1 and syn 4 conformers of NPCI, respectively. Each rotational transition is split into two Doppler components because the direction of the supersonic jet expansion is parallel to the standing wave in the Fabry-Pérot cavity of the spectrometer.
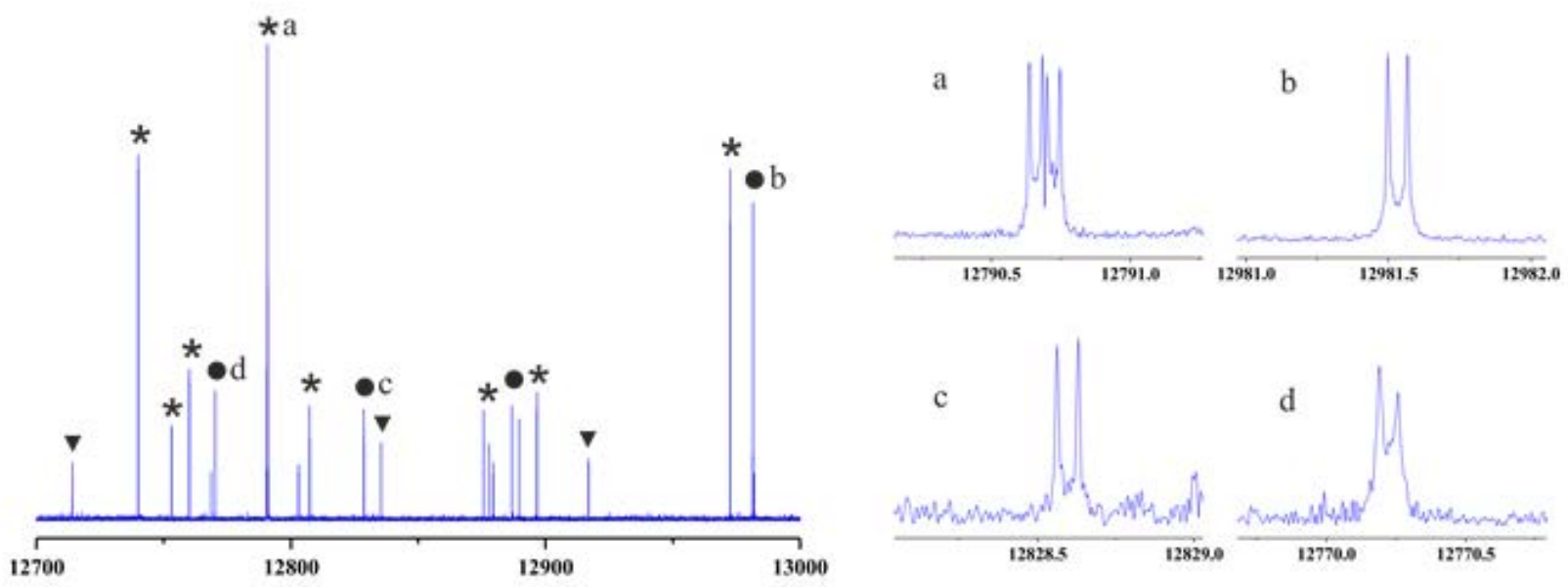